\title{
Osteocyte: a Cellular Basis for Mechanotransduction in Bone*
}

\author{
Guoliang GU**, Kosaku KURATA ***, Zhi CHEN** and Kalervo H. VÄÄNÄNEN** \\ ${ }^{* *}$ Institute of Biomedicine, Department of Anatomy, University of Turku \\ Kiinamyllynkatu 10, Turku, Finland \\ E-mail: guogu@utu.fi \\ *** Department of Biorobotics, Faculty of Engineering, Kyushu Sangyo University \\ 2-3-1 Matsukadai, Higashi-ku, Fukuoka, Japan
}

\begin{abstract}
Osteocyte is the most abundant cell type in bone, and the only cell type located inside the mineralized matrix. The striking structural design of bone predicts an important role for osteocytes in determining bone structure and function. Osteocytes are connected with each other via gap junctions and form a three dimensional cellular network in mineralized bone matrix. Recently, it has been shown that osteocytes are not only passive bystanders, but also have an active regulatory role in whole body phosphate and calcium metabolism. Osteocytes are cells which sense mechanical loading in bone. They respond to mechanical stimuli by producing and secreting several bioactive substances including nitric oxide and prostaglandins and thus transmit messages of loading to effector cells, like osteoblasts and osteoclasts. Present data suggest that osteocytes actively inhibit osteoclastic bone resorption. Whenever osteocytes die, this inhibitory effect is turned off and osteoclasts are activated. This mechanism of action could explain targeted remodeling in the region of stress induced microcracks happened. Osteocytes can also modulate osteoblasts function. In conclusion, osteocytes sense mechanical stimuli, transmit signals through cellular network and regulate osteoblast and osteoclast function during bone remodeling.
\end{abstract}

Key words: Osteocyte, Osteoblast, Osteoclast, Bone Remodeling, Gap Junction, Mechanotransduction, Signal Transduction Path Way

\section{Introduction}

The skeletal system is continuously subjected to repetitive loading due to weight bearing and muscle contractions. The loads imposed on bone determine its structure as described already in Wolff's law over one hundred years ago ${ }^{(1)}$. Bone is a dynamic tissue capable of adapting its structure to mechanical stimuli and repairing local structural damages by bone modeling and remodeling throughout the whole life. The bone modeling and remodeling processes are performed by basic multicellular units (BMU), which contain both bone resorbing as well as bone forming cells ${ }^{(2)(3)}$.

Osteocytes are the most abundant cell type in bone, being 10 times more abundant than osteoblasts ${ }^{(4)}$. The osteocyte is the only cell type inside mineralized bone matrix and human bone contains $13,900-19,400$ osteocytes per $\mathrm{mm}^{3}{ }^{(5)}$. Average size of cell body is $10-15 \mu \mathrm{m}$ and they are regularly spaced throughout the mineralized matrix. Each osteocyte radiates approximately 50 cell processes ${ }^{(6)}$ that run along small canaliculi and communicate with each other and with bone lining cells, osteoblasts and bone marrow cells ${ }^{(7)(8)}$. Osteocytes 
are thus ideally located to sense even minor changes in bone fluid flow and in 3-dimensional structure. They are the prime cellular candidates to initiate repairable responses culminating in remodeling and tissue adaptation. Sequences of bone remodeling process are described in Fig 1. In the beginning of remodeling process, osteoclasts migrate to the resorption site and start the resorption (Fig 1a). Recent studies indicated that damaged or apoptotic osteocytes (represented by dark-colored cells in the figure) provide an important role in deciding where osteoclasts start bone resorption. This mechanism called as targeted remodeling is discussed in section 3.5. When resorption proceeds, osteoblasts follow osteoclasts and start bone formation (Fig 1b) gradually filling the resorption cavity with a new osteon (Fig 1c). Bone synthetizing osteoblasts are already coupled to each other by gap junctions. During bone formation some of them become entrapped inside the matrix and gradually differentiate to osteocytes retaining gap junction mediated connections to surrounding cells (Fig 1d).

In this review, we will discuss cell biological features as well as mechanical role of osteocytes in bone metabolism. Understanding unique features of osteocytes would inspire not only researchers working in life sciences but also engineers working on bone mechanics.

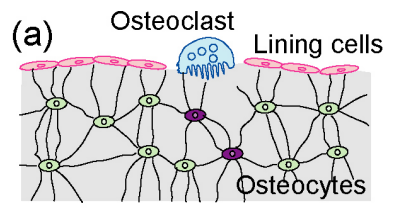

(b)

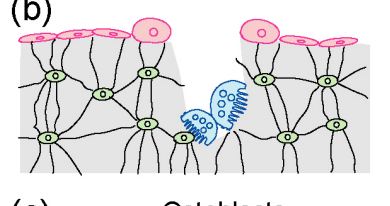

(c)

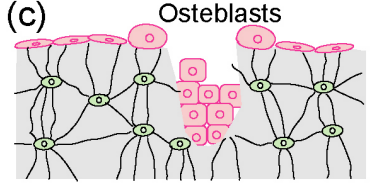

(d)

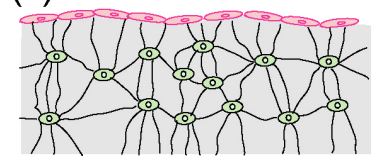

Fig. 1 Sequences of bone remodeling process.

(a)Osteoclast migration;

(b)Resorption; (c)Formation;

(d)Quiescent.

\section{Biological characteristics of osteocytes}

The current evidence shows that osteocytes are derived from osteoblasts. However, there are a lot of significant differences between osteocytes and osteoblasts. During osteocyte differentiation, the volume of cell body is reduced by about $30 \%$ during transition from a mature osteoblast to an early osteocyte, and further by about $70 \%$ when the osteocyte reaches full maturity ${ }^{(9)}$. They loose a large part of their cell organelles but gain long, slender cell processes by which these cells remain in contact with earlier embedded osteocytes, osteoblasts lining the bone surface, and bone marrow cells ${ }^{(8)(10)(11)}$.

The mature osteocyte is a stellate shaped cell. Cell body is enclosed within the small lacuna and slender long cellular processes reach into the canalicular system. Since bone matrix does not allow diffusion when fully mineralized, the canalicular network is used to transport nutrients to osteocytes and export their secretory products. In terms of mechanosensor concept, the most characteristic feature of osteocytes is their location inside the bone matrix and their connections to other cells via cytoplasmic extensions. This coupling of osteocytes to each other and to cells on the bone endocortical surface allows formation of multicellular syncytium, which could sense changes in bone geometry much more efficiently than single cells.

Osteocytes form cell to cell contacts, called gap junctions, which allow movement of small molecules directly from one cell to another with a minimal time delay ${ }^{(12)-(15)}$. Connexins, which are main molecular components of gap junctions can form complete channels between two cells or may form so called hemichannels for the secretion of specific molecules, like prostaglandins, into the extracellular fluid ${ }^{(16)}$.

At present we still lack an extensive and detailed global analysis of osteocyte's 
proteome. However, several proteins typical for osteocytes have been described. Some of them are subsequently expressed in osteocytes during their life cycle. Alkaline phosphatase (ALP) has been reported to be very low in preosteoblasts ${ }^{(17)}$, is high in osteoblasts and decreases parallel to the differentiation from osteoblast to osteocyte ${ }^{(18)(19)}$. ALP from osteoblasts is secreted into extracellular matrix in small vesicular structures called matrix vesicles, and it regulates matrix mineralization ${ }^{(20)}$. Osteocalcin, a small calcium binding protein, is a very specific product of osteoblasts and osteocytes. By using gene knockout technology, osteocalcin has been shown to be a negative regulator of bone mineralization (21). In addition to osteocalcin, several other proteins typical for osteoblasts are also expressed in osteocytes, such as osteopontin, osteonectin, etc ${ }^{(22)(23)}$.

Sclerostin is another protein that is expressed exclusively in osteocytes and inhibits mineralization ${ }^{(24)}$. Osteocytes and cell processes in both cortical and trabecular bone from normal adults showed strong positive staining for sclerostin ${ }^{(25)}$. Absent of sclerostin results in a high bone mass and a clinical disorder called sclerosteosis ${ }^{(26)(27)}$. Overexpression of the human sclerostin in mice induces osteoporotic phenotype, with a marked decrease in osteoblast activity ${ }^{(25)}$. Sclerostin may be one of the osteocyte-derived factors that is tranported to osteoblasts at the bone surface and inhibits bone formation. Since sclerostin expression is highly restricted to osteocytes, it may be a potential target for anabolic drug therapy.

Since all above-mentioned proteins are typical for both osteoblasts and osteocytes, a lot of work has been focused to identify osteocyte specific gene products. Dentin matrix protein 1 (DMP1) is an osteocyte-selective, extracellular matrix-associated phosphoprotein also found in other mineralizing tissues such as enamel, dentin, and cementum ${ }^{(28)(29)}$. DMP1 belongs to the SIBLING (small integrin binding ligand $N$-linked glycoprotein) family of extracellular matrix proteins that includes osteopontin, bone sialoprotein, dentin sialophosphoprotein, and matrix extracellular phosphoglycoprotein (MEPE). DMP1 is highly expressed in osteocytes and therefore a good marker for the osteocyte lineage ${ }^{(30)-(32)}$. DMP1 is specifically expressed along and in the canaliculi of osteocytes within the bone matrix suggesting a role in osteocyte function. It has been suggested that DMP1 regulates local mineralization processes that are carried out within the lacunae and canaliculi of osteocytes in mature bone, thus keeping the lacunae and canaliculi open to allow bone fluid flow ${ }^{(33)}$. A function for DMP1 in bone biology may thus be to define the structural, mechanical, and material properties of the canalicular and lacunar wall. The stiffness of this wall could play an important role in detecting and transmitting mechanical signals.

At 1986, Nijweide and Mulder developed an osteocyte specific monoclonal antibody Mab OB $7.3^{(34)}$, and in later studies the antigen was revealed to be a product of chicken phosphate-regulating gene with homology to endopeptides on the X chromosome (PHEX) . PHEX is expressed at much higher levels in osteocytes compared to osteoblasts ${ }^{(35)}$.

Fibroblast growth factor 23 (FGF23) was originally identified using exon prediction programs on chromosome 12p12 genomic DNA sequence from Human Genome Project ${ }^{(36)}$. It turned out to be a key humoral factor in phosphate homeostasis and skeletogenesis. Osteocytes are a principal source of circulating FGF23 ${ }^{(37)(38)}$. There is evidence now for a hormone/enzyme/extracellular matrix protein cascade involving FGF23, PHEX, and MEPE that regulates systemic phosphate homeostasis and bone mineralization ${ }^{(39)(40)}$. This indicates that osteocytes may have an important role also in the phosphate metabolism of the whole organism.

\section{Mechantransduction}

\subsection{Microstructure of bone}


From the mechanics point of view, bone is a tissue that almost ideally fulfills the mechanical demands. Bones are stiff enough and their strength is adequate for daily usage without fractures. While at the same time, bones are sufficiently light for the movement, adaptable to environmental factors, and are repairable.

Bone is a lamellar composite material (mineral and organic phase) with different type of porosity. Although dimensions of bone microstructure are not always the same in different species and developing stage, there are basically three levels of porosity (according to the size) containing bone fluid within the bone. In human bone, the first and largest pores are around blood vessels, named Haversian canals (Fig 2a), which are connected by Volkmann's canals (about 6 to $70 \mu \mathrm{m}$ diameter) ${ }^{(41)}$. Lacunar-canalicular porosity by which osteocytes obtain nutrients and dispose their products is the second level of porosity (Fig 2b), and is much smaller (lacunae: about $10 \mu \mathrm{m}$ diameter; canaliculi: about $400 \mathrm{~nm}$ diameter) ${ }^{(42)}$. The third level of porosity could be observed within the lacunar-canalicular channels (Fig 2c), where there is a gel-like fiber matrix spacing of approximately $7 \mathrm{~nm}$ to fill the pericellular fluid space ${ }^{(43)}$. With different tracers, the cut-off size of lacunar-canalicular porosity has been shown to be between 6-10 nm for molecular movement from bone capillaries to osteocytic lacunae ${ }^{(44)}$.

Each osteocyte is enclosed within its mineralized lacuna and has a number of cytoplasmic processes. Immuno-fluorescence microscopy has been used to study chick calvarial osteocytes, showing that single osteocyte has as many as approximately 50 cytoplasmic processes ${ }^{(6)}$. These processes are arrayed in three-dimensional manner that permits each osteocyte to be connected with several neighbor osteocytes, or even osteoblasts and osteoclasts on the bone surface. The small space between the plasma membrane of cell process and the canalicular wall is filled with bone fluid. Bone structure provides a dynamic flow environment for cells. Pericellular fluid could act as a carrier of mechanical, electrical and chemical signals between the systemic circulation and bone cells. It provides not only nutrients, but also an extracellular network for communication among osteocytes, osteoblasts and osteoclasts.

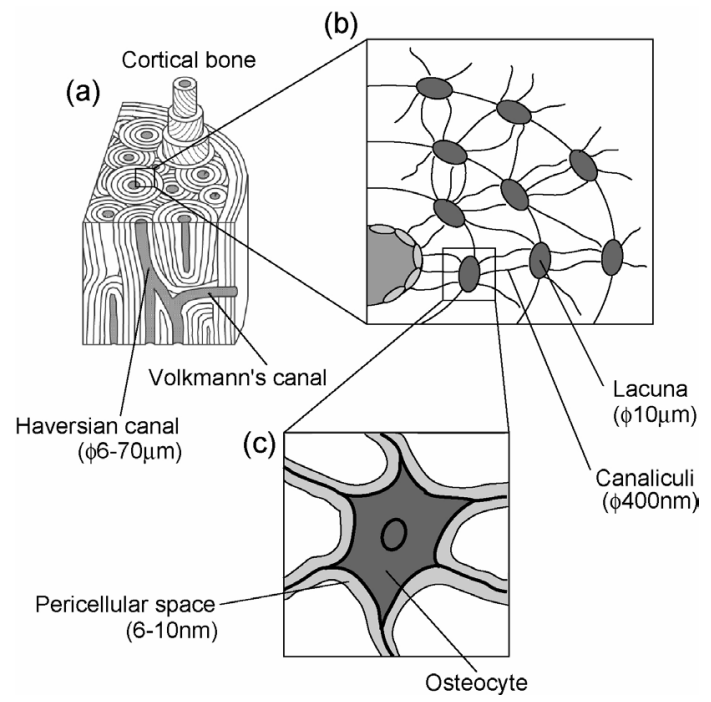

Fig 2 Microstructure of cortical bone different type of porosity. (a)Haversian and Volkmann's canals;

(b)Lacunar-canalicular porosity; (c)Pericellular fluid space.

\subsection{What are the mechanical signals reaching osteocytes}

The mechanical loads applied on bone generate mechanical signals that are sensed at the cellular level. Osteocytes are regarded as the mechanosensory cells that send signals to other bone cells to initiate remodeling. In principle, there are two ways how mechanical signals can reach osteocytes: via extracellular matrix or extracellular fluid ${ }^{(43),(45)-(47)}$.

It has been suggested that mechanical loading induces interstitial fluid flow, which results in shear stresses on the osteocyte plasma membrane or deformation of the cytoskeleton in the processes leading to the activation of various intracellular signaling pathways ${ }^{(43),(48)-(51)}$. As bone tissue is loaded in vivo, fluid motions along lacuna-canalicular 
system are dynamic and oscillatory in nature. There is still insufficient quantification of lacuna-canalicular fluid flow actually occurring in vivo. Oscillating flow may be the most appropriate flow regime for in vitro studies, since they are more physiologic than steady or pulsatile flow. However, oscillating flow was much less potent stimulator of bone cells than either steady or pulsing flow when monitored by changes in intracellular calcium concentration ${ }^{(52)}$. Different fluid flow regimens may produce different results. Mechanosensitivity of bone cells to oscillating fluid flow maybe modulated by chemotransport or other mechanisms, such as gap junctions ${ }^{(53)}$. It is hypothesized that multiple mechanosensitive mechanisms are present in bone cells and that these mechanisms are activated at different levels of stimulus.

In another aspect, osteocytes can be stimulated by direct deformation via mechanical stimulation of the perilacunar bone matrix. Loading induced strain in bone can be mediated to osteocytes via extracellular matrix - cell plasmamembrane interactions. Long cellular processes inside the canalicular system and their interactions to each other and to the wall of the canaliculi favor detection of even minor changes in the internal geometry of bone. Thus it is likely that a driving force for the development of syncytium cellular structure during the evolution has been enhanced mechanosensitivity. In the experimental in vitro studies, several types of mechanical stimuli of plasma membrane have been applied in addition to fluid flow, one being direct deformation by micromanipulators or microneedles ${ }^{(54)}$.

Concerning sensitivity to mechanical stimulation, the cells have been considered to be less responsive to direct strain than to fluid flow ${ }^{(45)}$. Cells were subjected to so-called physiological strain that was defined as macroscopic surface strain on bone. However, local strain level around osteocytes cannot be determined by macroscopic estimation, and recent microscopic strain measurement ${ }^{(55)}$ and finite element analysis (56) showed that local tissue strain around osteocyte lacunae was significantly greater than the macroscopic strain, which means osteocytes have a potential to show much greater respond to direct deformation in microscopic levels.

In Fig 3, we have shown a flow chart of mechanotransduction in bone tissue. In the following chapters we will shortly discuss about each specific item of

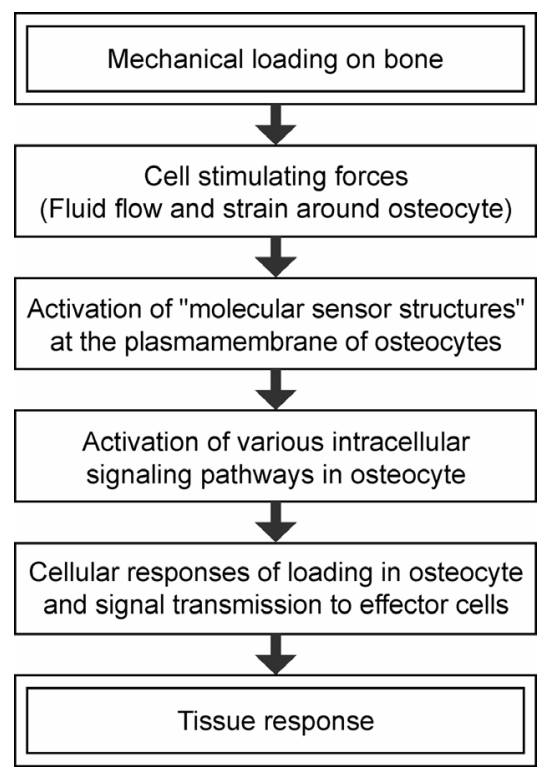

Fig.3 Flow chart of mechanical loading on osteocytes. mechanotransduction.

\subsection{How osteocytes sense mechanical loading induced signals}

Adaptation of tissue to mechanical loading can happen only if cells in the tissue modulate their activities due to loading. In order to induce adaptation to mechanical stimulus, cells must finally undergo changes of gene transcription. In multicellular tissues, the target cells of mechanical loading may not be the actual effector cells, which are responsible for tissue remodeling. In case of osteocytes, this is most likely the case. Osteocytes sense the mechanical loading, and translate it into "chemical language" for the effector cells. Several studies have suggested that osteocytes execute their mechanosensory function by the transduction of mechanical loads into biochemical signals capable of influencing osteoblasts and osteoclasts ${ }^{(57)-(59)}$. 
It is still not exactly clear how the physical stimulus being converted into the cellular responses. There are several different possibilities and most likely more than one is operating also in osteocytes. Several adhesion proteins such as integrins can mediate strain of extracellular matrix to intracellular signaling pathways. In addition, cells may sense fluid flow by their stress induced ion channels, gap junctions and primary cilium ${ }^{(60)(61)}$. In Fig 4 , we have outlined potential molecular targets of loading and their downstream signaling pathways.

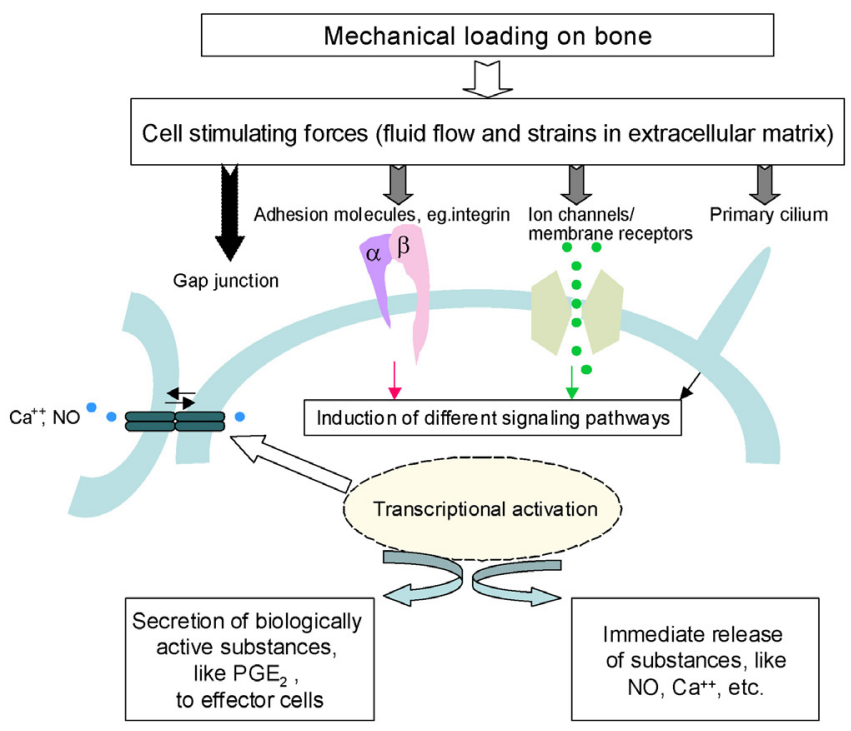

Fig.4 Summary of mechanotransdution in osteocytes.

Cells use specific transmembrane receptors, such as integrins, to mechanically couple their cytoskeletal network to extracellular matrix ${ }^{(62)}$. Integrins are transmembrane proteins that made up of two heterodimers $\alpha$ and $\beta$. They bind to extracellular matrix on the outside of cells, and are linked to actin cytoskeleton via intracellular $\beta$-subunit at specialized sites known as focal adhesions. Intracellular $\beta$-subunit interacts with molecules such as vinculin, talin, paxillin, and $\alpha$-actinin. Cell stimulating forces were mediated by this integrin-cytoskeleton complex and transduced through the cell membrane in both direction: binding of ligands to integrins, transmits signals into the cell and results in cytoskeletal re-organization, gene expression and cellular differentiation; on the other hand, signals from the cell can also be propagated through integrins and regulate integrin ligand-binding affinity and cell adhesion ${ }^{(63)(64)}$. Among various integrins, $\alpha_{V} \beta_{3}$ integrin was reported to be upregulated by mechanical strain in osteoblasts. This type of integrin is also highly expressed in human osteocytes. Miyauchi et al. studied on rat primary osteocytes, and suggested that interaction between $\alpha_{V} \beta_{3}$ integrin and extracellular matrix influenced mechanosensing ${ }^{(65)}$. Moreover, focal adhesion-related protein, vinculin, provides an important signal transduction route in osteocytes. Differences in expressing portion of vinculin have been reported between chick calvarial osteocytes and osteoblasts and osteocytes made contact with the extracellular matrix via small attachment points which colocalized with vinculin ${ }^{(66)(67)}$. This finding could explain the different sensitivity of cell types to mechanical stimulation. Actin-binding protein fimbrin is also play a prominent role especially in osteocytic cell processes ${ }^{(68)}$.

Cells may also utilize other cell surface molecules to sense mechanical stimulus, for example ion channels, G-proteins, and P2 receptors. Mechanosensitive or stretch-activated ion channels have been identified in osteoblasts ${ }^{(69)-(71)}$, and were also found in chicken and rat primary osteocytes ${ }^{(72)}$. They demonstrated that stretch loading by swelling rapidly increased $\mathrm{Ca}^{2+}$ influx, mainly along the cell processes, which leads to consequent 
intracellular responses. It was also demonstrated that ATP signaling through P2X7 receptor is necessary for mechanically induced release of prostaglandins by osteoblasts and osteocytes $^{(73)}$.

One potential mechanism how external force, for instance fluid flow, can induce cellular events is via primary cilium. Primary cilium is a single elongated microvillar projection found on the surface of most terminally differentiated cells, like chondroblasts and osteoblasts ${ }^{(74)}$. Malone et al. reported that osteocytic cell line MLO-Y4 deflected its primary cilium during fluid flow and increased cyclooxygenase2 (COX2) gene expression independently of $\mathrm{Ca}^{2+}$ flux and stretch-activated ion channels ${ }^{(75)}$. However, the COX2 expression was inhibited by abrogating primary cilium, which indicates important role of primary cilium as a mechanosensing structure. Our preliminary results have indicated that mouse primary osteocytes also contain primary cilia.

Osteocytes form three-dimensional cellular network in the mineralized bone matrix. Gap junctions are transmembrane channels that link the cytoplasms of adjacent osteocytes. Both isolated primary osteocytes ${ }^{(14)(15)}$ and osteocytic cell line MLO-Y4 ${ }^{(13)}$ can also form cell-to-cell contact with functional gap junctions in vitro. Mechanical stimulation has been shown to increase expression of connexins, a major molecular component of gap junctions, in vitro and in vivo, thus suggesting that mechanical stimulation may enhance cell-cell communication via gap junctions ${ }^{(16)(76)}$. Whatever is the signaling pathway, which mechanical stimulus induces, it must either lead to the immediate release of existing signaling molecules or should lead to modifications of gene transcription in order to induce more delayed responses.

\subsection{How molecular sensors induce and propagate signaling further inside osteocytes}

Mechanochemical conversion may occur simultaneously at several sites inside tissues or may originate from a single sensory cell. At present we do not know if all osteocytes are similarly responding to mechanical stimuli or if there is a population of osteocytes, which is more sensitive to loading. Very little is known what potential sensor mechanisms are operative in osteocytes, since the research so far has been concentrated to detect changes in the intracellular mediators of signal transduction.

One of the first intracellular signaling pathways linked to mechanotranduction is intracellular calcium signaling, which is an important mechanism in many cellular processes ${ }^{(77)}$. Loading induced rapid change in cytoplasmic calcium concentration could be due to release of calcium from the intracellular pool ${ }^{(78)}$. The conclusion that intracellular calcium signaling is an important mediator of mechanical loading is supported by the observations that mechanical stimulus does not induce mechanically regulated changes in gene expression when calcium signaling is blocked ${ }^{(79)(80)}$. The measurement of intracellular calcium transitions is thought to be an useful indicator for evaluating the short term mechanosensory responses in osteocytes ${ }^{(80)}$. In addition to direct activation of intracellular signaling cascades, influx of a charged species such as calcium can also alter membrane potential and activate voltage sensitive channels, which are not directly mechanosensitive ${ }^{(81)}$. Intercellular calcium waves are calcium transients that spread from cell to cell in response to different stimuli. Direct cell - cell contacts via gap junctions offers a rapid and efficient spread of signals throughout all osteocytes in the same osteon.

Nitric Oxide (NO) is a small and highly reactive molecule, which act as a second messenger exhibiting wide range of physiological and pathophysological effects ${ }^{(82)}$. Nitric oxide has pleiotropic effects in bone cells, and potently decreases resorption through decreasing osteoclast formation and activity ${ }^{(83)}$. NO is released from isolated primary osteocytes in response to fluid flow, likely due to activation of endothelial nitric oxide synthase ${ }^{(84)(85)}$. It has been shown that NO regulates the ratio of RANKL/osteoprotegerin in stromal cells ${ }^{(83)(86)}$. It is thus possible that NO is one of the major intercellular mediators of 
loading effects.

\subsection{How osteocytes regulate bone metabolism}

In order to transport loading effects to changes in bone structure and metabolism, osteocytes must somehow be able to regulate, either directly or indirectly, the differentiation and/or function of osteoblasts and osteoclasts, the actual "working cells" in bone. There is now a lot of in vitro evidence and some in vivo evidence, although still rather fragmentary, that this really happens. In addition, it is also possible that osteocytes directly modify bone matrix in response to mechanical loading or immobilization. It has been suggested that osteocytes may regulate matrix degradation/synthesis or mineralization/demineralization in their immediate vicinity ${ }^{(87)(88)}$. However, it is too early to say what will be the actual importance of this mechanism compared to those effects mediated via bone remodeling.

Activation of signaling pathways in osteocytes can lead to immediate or delayed responses in osteocytes. Both of these mechanisms are obviously important in the regulation of osteoclasts and osteoblasts. Immediate responses can take place and used to transmit loading effects to effector cells without immediate transcriptional activity in osteocytes. These effects could be mediated via gap junctions, for instance using rapid intercellular calcium wave. Activation of other cells may also happen by secreting substances that can be formed without transcriptional activity, like NO and some prostaglandins, which are both potent regulators of osteoblastic and osteoclastic activity.

Direct signal transduction via gap junctions is also an example of paracrine type of action. It has been reported that oscillating fluid flow regulates gap junction communication in osteocytic cell line MLO-Y4 by ERK1/2 MAP kinase ${ }^{(89)}$. In addition to regulating cell-cell communication, connexins can also form regulatory hemichannels between osteocytes and its extracellular environment. Mechanical strain opens connexin 43 (Cx43) hemichannels in both primary osteocytes and cell line for the release of prostaglandin ${ }^{(16)}$. New data with MLO-Y4 osteocytic cells demonstrate that hemichannels formed by $\mathrm{Cx} 43$ are activated in response to oscillatory fluid flow and are responsible for ATP release ${ }^{(90)}$. Study by Cherian et al. has shown that prostaglandin $\mathrm{E}_{2}\left(\mathrm{PGE}_{2}\right)$ is directly released through $\mathrm{Cx} 43$ hemichannels ${ }^{(16)}$. While in another report, $\mathrm{PGE}_{2}$ release is mediated by activation of P2 receptors ${ }^{(90)}$. It is likely that multiple mechanosensitive mechanisms are present in osteocytes and these mechanisms are activated at different levels of stimulus.

Transcriptional activation can lead to enhanced survival of osteocytes or it can induce production of cytokines and growth factors, which can be used as mediators to activate other cells in the immediate neighborhood (paracrine effects) or in longer distance (endocrine effects). The best characterized example of endocrine response is the production and secretion of FGF23, which clearly has remark hormone like effects in kidney ${ }^{(91)}$. As mentioned earlier, several examples are already available supporting the paracrine function of osteocytes including secretion of $\mathrm{NO}$ and $\mathrm{PGE}_{2}$, which clearly have strong effects on osteoblasts and osteoclasts. Long term effects of loading will always need modulation of transcriptional activity in osteocytes. Various studies have shown that many different genes are either up-regulated or down-regulated in osteocytes after mechanical loading ${ }^{(92)-(94)}$. Altered gene expression of important transcriptional regulators such as c-fos and c-jun are observed in response to mechanical stimulus ${ }^{(95)}$. It has also been shown that the expression of both DMP1, a promoter of mineralization, and MEPE, an inhibitor of mineralization, are sequentially increased due to loading ${ }^{(33)}$. This raises the question whether also whole body mineral metabolism could be regulated by mechanical loading ${ }^{(96)}$. However, we are still missing comprehensive studies of loading effects on gene expression in osteocytes. Now when global analysis of gene expression is possible from various different animal species, it would be interesting to compare effects of different loading patterns on osteocytic gene expression in cortical and trabecular bone. 
Osteocytes can regulate bone remodeling at several different stages. Since osteoclasts begin the local remodeling cycle, it has been suggested that osteocytes direct osteoclastic precursors to the resorption site. In principle this could happen either via positive and/or negative regulation. In vivo evidence suggests that reduced mechanical forces lead to increased prevalence of osteocyte apoptosis. These cellular changes initiate a serial of events comprising a transient decrease in bone formation followed by an increase in resorption in the vicinity of the dying osteocytes, leading to loss of bone mineral and strength ${ }^{(97)}$. We have provided evidence that both rat primary osteocytes and osteocytic cell line MLO-Y4 secrete substances that are inhibitory to osteoclasts. As soon as osteocytes stop secreting these substances, this inhibitory effect disappears and allows osteoclasts to start resorption. In addition, ageing or injured osteocytes may also start to secrete chemotactic signals which attract osteoclasts to the resorption site ${ }^{(98)(99)}$. For instance, histological observation after fatigue-loading to rat ulnae showed that strong associations between microcracks of bone matrix, osteocyte apoptosis, and subsequent bone resorption (100). Osteocytic cell line studies also indicated that mechanically damaged osteocytes secreted osteoclast-differentiating factors and locally recruited osteoclastic cells ${ }^{(101)(102)}$. Overall, this dual regulation involving both negative and positive signaling would nicely explain bone resorption targeted to the specific sites, or targeted remodeling. Damaged or apoptotic osteocytes (represented by dark-colored cells in the Fig 1a) provide an important role in deciding where osteoclasts start bone resorption.

Osteocytes transmit biophysical signals to osteoblasts by intercellular communications via gap junction ${ }^{(103)(104)}$. With a coculture system of osteocytic and osteoblastic cell lines mimic in vivo situation, it has been shown that mechanically stimulated osteocytes regulate osteoblast activity ${ }^{(104)}$. Heino reported that conditioned medium from MLO-Y4 osteocytic cell line, have a stimulatory effect on osteoblast differentiation ${ }^{(105)}$. Osteocytes produce signaling molecules such as NO, which modulate the activity of bone forming cells, the osteoblasts ${ }^{(57)(106)(107)}$. A plausible inhibition theory hypothesized by Marotti and Martin suggests that the osteocyte sends an inhibitory signal through its processes to the osteoblasts and bone lining cells, and controls the diminishing apposition rate during refilling of osteonal basic multicellular units ${ }^{(108)(109)}$. It has been demonstrated that sclerostin is secreted by osteocytes and negatively regulates osteoblastic bone formation by antagonizing BMP and WNT signals ${ }^{(25)(110)}$. This makes sclerostin as an osteocyte - derived regulator of osteoblastic function. DMP1 is highly expressed in osteocytes as described earlier, it serves physiological function in osteoblasts and regulates bone mineralization ${ }^{(111)(112)}$. With a novel transgenic model by specific expression of diphtheria toxin (DT) receptor in osteocytes, Tatsumi et al. also demonstrates that osteocytes control osteoclast differentiation indirectly through modulation of RANKL expression in osteoblasts. Their results also support that osteocytes play a crucial role in mechanotransduction ${ }^{(113)}$.

\section{Conclusion}

Present data suggest that osteocytes are the main regulators of the bone remodeling and metabolism. They sense the mechanical loading and transmit the subsequent signals to the effector cells, namely osteoclasts and osteoblasts, modulating bone resorption and bone formation, respectively. Several important questions remain, however, unanswered concerning the details of molecular mechanisms that send and translate the mechanical stimuli into chemical language, which is understood by effector cells. Better insight into the molecular mechanisms would allow us to develop better physical exercise programs and prevent osteoporotic fractures. It will also open new possibilities to develop novel drug therapies for metabolic bone disease using osteocytes as target cells. 


\section{References}

(1) Wolff, J., Das Gesetz der Transformation der Knochen, (1892), Verlag von August Hirschwald, Berlin (English translation "The Law of Bone Remodeling" by Maquet, P and Furlong, R. was published by Springer-Verlag, Berlin in 1986).

(2) Frost, H.M., Measurement of Human Bone Formation by Means of Tetracycline Labelling, Canadian Journal of Biochemistry and Physiology, Vol.41 (1963), pp.31-42.

(3) Lorenzo, J., Interactions between Immune and Bone Cells: New Insights with Many Remaining Questions, Journal of Clinical Investigation, Vol.106 (2000), pp.749-752.

(4) Jande, S.S. and Belanger, L.F., The Life Cycle of the Osteocyte, Clinical Orthopaedics and Related Research, Vol.94 (1973), pp.281-305.

(5) Sissons H.A. and O'Connor P., Quantitative Histology of Osteocyte Lacunae in Normal Human Cortical Bone, Calcified Tissue Research, Suppl. (1977), pp.530-533.

(6) Sugawara, Y., Kamioka, H., Honjo, T., Tezuka, K. and Takano-Yamamoto, T. Three-Dimensional Reconstruction of Chick Calvarial Osteocytes and Their Cell Processes Using Confocal Microscopy, Bone, Vol.36 (2005), pp.877-883.

(7) Donahue, H.J., Gap Junctions and Biophysical Regulation of Bone Cell Differentiation, Bone, Vol.26 (2000), pp.417-422.

(8) Kamioka, H., Honjo, T. and Takano-Yamamoto, T., A Three-Dimensional Distribution of Osteocyte Processes Revealed by the Combination of Confocal Laser Scanning Microscopy and Differential Interference Contrast Microscopy, Bone, Vol.28 (2001), pp.145-149.

(9) Marotti, G., Zallone, A.Z. and Ledda, M., Number, Size and Arrangement of Osteoblasts in Osteons at Different Stages of Formation, Calcified Tissue Research, Vol.21, Suppl. (1976), pp.96-101.

(10) Palumbo, C., Palazzini, S. and Marotti, G., Morphological Study of Intercellular Junctions during Osteocyte Differentiation, Bone, Vol.11 (1990), pp.401-406.

(11) Nefussi, J.R., Sautier, J.M., Nicolas, V. and Forest, N., How Osteoblasts Become Osteocytes: A Decreasing Matrix Forming Process, Journal de Biologie Buccale, Vol.19 (1991), pp.75-82.

(12) Doty, S.B., Morphological Evidence of Gap Junctions between Bone Cells, Calcified Tissue International, Vol.33 (1981), pp.509-512.

(13) Cheng, B., Zhao, S., Luo, J., Sprague, E., Bonewald, L.F. and Jiang, J.X., Expression of Functional Gap Junctions and Regulation by Fluid Flow in Osteocyte-Like MLO-Y4 Cells, Journal of Bone and Mineral Research, Vol.16 (2001), pp.249-259.

(14) Gu, G., Nars, M., Hentunen, T.A., Metsikko, K. and Vaananen, H.K., Isolated Primary Osteocytes Express Functional Gap Junctions in Vitro, Cell and Tissue Research, Vol.323 (2006), pp.263-271.

(15) Kamioka, H., Ishihara, Y., Ris, H., Murshid, S.A., Sugawara, Y., Takano-Yamamoto, T. and Lim, S.S., Primary Cultures of Chick Osteocytes Retain Functional Gap Junctions between Osteocytes and between Osteocytes and Osteoblasts, Microscopy and Microanalysis, Vol.13 (2007), pp.108-117.

(16) Cherian, P.P., Siller-Jackson, A.J., Gu, S., Wang, X., Bonewald, L.F., Sprague, E. and Jiang, J.X., Mechanical Strain Opens Connexin 43 Hemichannels in Osteocytes: A Novel Mechanism for the Release of Prostaglandin, Molecular Biology of the Cell, Vol.16 (2005), pp.3100-3106.

(17) Reilly, T.M., Seldes, R., Luchetti, W. and Brighton, C.T., Similarities in the Phenotypic Expression of Pericytes and Bone Cells, Clinical Orthopaedics and Related Research, Vol.346 (1998), pp.95-103.

(18) Bruder, S.P. and Caplan, A.I., Terminal Differentiation of Osteogenic Cells in the Embryonic Chick Tibia Is Revealed by a Monoclonal Antibody Against Osteocytes, Bone, Vol.11 (1990), pp.189-198. 
(19) Bruder, S.P. and Caplan, A.I., Osteogenic Cell Lineage Analysis Is Facilitated by Organ Cultures of Embryonic Chick Periosteum, Developmental Biology, No.141 (1990), pp.319-329.

(20) Morris, D.C., Masuhara, K., Takaoka, K., Ono, K. and Anderson, H.C., Immunolocalization of Alkaline Phosphatase in Osteoblasts and Matrix Vesicles of Human Fetal Bone, Bone and Mineral, Vol.19 (1992), pp.287-298.

(21) Ducy, P., Desbois, C., Boyce, B., Pinero, G., Story, B., Dunstan, C., Smith, E., Bonadio, J., Goldstein, S., Gundberg, C., Bradley, A. and Karsenty, G., Increased Bone Formation in Osteocalcin-Deficient Mice, Nature, Vol.382 (1996), pp.448-452.

(22) Hultenby, K., Reinholt, F.P., Oldberg, A. and Heinegard, D., Ultrastructural Immunolocalization of Osteopontin in Metaphyseal and Cortical Bone, Matrix, Vol.11 (1991), pp.206-213.

(23) Mark, M.P., Butler, W.T., Prince, C.W., Finkelman, R.D. and Ruch, J.V., Developmental Expression of 44-kDa Bone Phosphoprotein (Osteopontin) and Bone Gamma-Carboxyglutamic Acid (Gla)-Containing Protein (Osteocalcin) in Calcifying Tissues of Rat, Differentiation, Vol.37 (1988), pp.123-136.

(24) Van Bezooijen, R.L., Roelen, B.A., Visser, A., Van Der Wee-Pals, L., De Wilt, E., Karperien, M., Hamersma, H., Papapoulos, S.E., Ten Dijke, P. and Lowik, C.W., Sclerostin Is an Osteocyte-Expressed Negative Regulator of Bone Formation, but Not a Classical BMP Antagonist, The Journal of Experimental Medicine, Vol.199 (2004), pp.805-814.

(25) Winkler, D.G., Sutherland, M.K., Geoghegan, J.C., Yu, C., Hayes, T., Skonier, J.E., Shpektor, D., Jonas, M., Kovacevich, B.R., Staehling-Hampton, K., Appleby, M., Brunkow, M.E. and Latham, J.A., Osteocyte Control of Bone Formation via Sclerostin, a Novel BMP Antagonist, The EMBO Journal, Vol.22 (2003), pp.6267-6276.

(26) Balemans, W., Ebeling, M., Patel, N., Van Hul, E., Olson, P., Dioszegi, M., Lacza, C., Wuyts, W., Van Den Ende, J., Willems, P., Paes-Alves, A.F., Hill, S., Bueno, M., Ramos, F.J., Tacconi, P., Dikkers, F.G., Stratakis, C., Lindpaintner, K., Vickery, B., Foernzler, D. and Van Hul, W., Increased Bone Density in Sclerosteosis Is Due to the Deficiency of a Novel Secreted Protein (SOST), Human Molecular Genetics, Vol.10 (2001), pp.537-543.

(27) Brunkow, M.E., Gardner, J.C., Van Ness, J., Paeper, B.W., Kovacevich, B.R., Proll, S., Skonier, J.E., Zhao, L., Sabo, P.J., Fu, Y., Alisch, R.S., Gillett, L., Colbert, T., Tacconi, P., Galas, D., Hamersma, H., Beighton, P. and Mulligan, J., Bone Dysplasia Sclerosteosis Results from Loss of the SOST Gene Product, a Novel Cystine Knot-Containing Protein, American Journal of Human Genetics, Vol.68 (2001), pp.577-589.

(28) George, A., Gui, J., Jenkins, N.A., Gilbert, D.J., Copeland, N.G. and Veis, A., In Situ Localization and Chromosomal Mapping of the AG1 (Dmp1) Gene, The Journal of Histochemistry and Cytochemistry, Vol.42 (1994), pp.1527-1531.

(29) Macdougall, M., Gu, T.T., Luan, X., Simmons, D. and Chen, J., Identification of a Novel Isoform of Mouse Dentin Matrix Protein 1: Spatial Expression in Mineralized Tissues, Journal of Bone and Mineral Research, Vol.13 (1998), pp.422-431.

(30) Toyosawa, S., Shintani, S., Fujiwara, T., Ooshima, T., Sato, A., Ijuhin, N. and Komori, T., Dentin Matrix Protein 1 Is Predominantly Expressed in Chicken and Rat Osteocytes but Not in Osteoblasts, Journal of Bone and Mineral Research, Vol.16 (2001), pp.2017-2026.

(31) Toyosawa, S., Kanatani, N., Shintani, S., Kobata, M., Yuki, M., Kishino, M., Ijuhin, N. and Komori, T., Expression of Dentin Matrix Protein 1 (DMP1) during Fracture Healing, Bone, Vol.35 (2004), pp.553-561.

(32) Kalajzic, I., Braut, A., Guo, D., Jiang, X., Kronenberg, M.S., Mina, M., Harris, M.A., Harris, S.E. and Rowe, D.W., Dentin Matrix Protein 1 Expression during Osteoblastic Differentiation, Generation of an Osteocyte GFP-Transgene, Bone, Vol.35 (2004), pp.74-82.

(33) Gluhak-Heinrich, J., Ye, L., Bonewald, L.F., Feng, J.Q., MacDougall, M., Harris, S.E. and 
Pavlin, D., Mechanical Loading Stimulates Dentin Matrix Protein 1 (DMP1) Expression in Osteocytes in Vivo, Journal of Bone and Mineral Research, Vol.18 (2003), pp.807-817.

(34) Nijweide, P.J. and Mulder, R.J., Identification of Osteocytes in Osteoblast-Like Cell Cultures Using a Monoclonal Antibody Specifically Directed Against Osteocytes, Histochemistry, Vol.84 (1986), pp.342-347.

(35) Westbroek, I., De Rooij, K.E. and Nijweide, P.J., Osteocyte-Specific Monoclonal Antibody Mab OB7.3 Is Directed Against Phex Protein, Journal of Bone and Mineral Research, Vol.17 (2002), pp.845-853.

(36) ADHR Consortium, Autosomal Dominant Hypophosphataemic Rickets Is Associated with Mutations in FGF23, Nature Genetics, Vol.26 (2000), pp.345-348.

(37) Urakawa, I., Yamazaki, Y., Shimada, T., Iijima, K., Hasegawa, H., Okawa, K., Fujita, T., Fukumoto, S. and Yamashita, T., Klotho Converts Canonical FGF Receptor into a Specific Receptor for FGF23, Nature, Vol.444 (2006), pp.770-774.

(38) Yoshiko, Y., Wang, H., Minamizaki, T., Ijuin, C., Yamamoto, R., Suemune, S., Kozai, K., Tanne, K., Aubin, J.E. and Maeda, N., Mineralized Tissue Cells Are a Principal Source of FGF23, Bone, Vol.40 (2007), pp.1565-1573.

(39) Quarles, L.D., FGF23, PHEX, and MEPE Regulation of Phosphate Homeostasis and Skeletal Mineralization, American Journal of Physiology, Endocrinology and Metabolism, Vol.285 (2003), pp.E1-E9.

(40) Rowe, P.S., The Wrickkened Pathways of FGF23, MEPE and PHEX, Critical Reviews in Oral Biology and Medicine, Vol.15 (2004), pp.264-281.

(41) Cooper, R.R., Milgram, J.W. and Robinson, R.A., Morphology of the Osteon. An Electron Microscopic Study, Journal of Bone and Joint Surgery, American Volume, Vol.48 (1966), pp.1239-1271.

(42) Piekarski, K. and Munro, M., Transport Mechanism Operating between Blood Supply and Osteocytes in Long Bones, Nature, Vol.269 (1977), pp.80-82.

(43) Cowin, S.C., Weinbaum, S. and Zeng, Y., A Case for Bone Canaliculi as the Anatomical Site of Strain Generated Potentials, Journal of Biomechanics, Vol.28 (1995), pp.1281-1297.

(44) Wang, L., Ciani, C., Doty, S.B. and Fritton, S.P., Delineating Bone's Interstitial Fluid Pathway in Vivo, Bone, Vol.34 (2004), pp.499-509.

(45) Owan, I., Burr, D.B., Turner, C.H., Qiu, J., Tu, Y., Onyia, J.E. and Duncan, R.L., Mechanotransduction in Bone: Osteoblasts Are More Responsive to Fluid Forces Than Mechanical Strain, The American Journal of Physiology, Vol.273 (1997), pp.C810-C815.

(46) Hung, C.T., Allen, F.D., Pollack, S.R. and Brighton, C.T., Intracellular Ca2+ Stores and Extracellular $\mathrm{Ca} 2+$ Are Required in the Real-Time $\mathrm{Ca} 2+$ Response of Bone Cells Experiencing Fluid Flow, Journal of Biomechanics, Vol.29 (1996), pp.1411-1417.

(47) Reich, K.M., Gay, C.V. and Frangos, J.A., Fluid Shear Stress as a Mediator of Osteoblast Cyclic Adenosine Monophosphate Production, Journal of Cellular Physiology, Vol.143 (1990), pp.100-104.

(48) Hillsley, M.V. and Frangos, J.A., Bone Tissue Engineering: The Role of Interstitial Fluid Flow, Biotechnology and Bioengineering, Vol.43 (1994), pp.573-581.

(49) Turner, C.H., Forwood, M.R. and Otter, M.W., Mechanotransduction in Bone: Do Bone Cells Act as Sensors of Fluid Flow?, The FASEB Journal, Vol.8 (1994), pp.875-878.

(50) Weinbaum, S., Guo, P. and You, L., A New View of Mechanotransduction and Strain Amplification in Cells with Microvilli and Cell Processes, Biorheology, Vol.38 (2001), pp.119-142.

(51) You, L., Cowin, S.C., Schaffler, M.B. and Weinbaum, S.A., Model for Strain Amplification in the Actin Cytoskeleton of Osteocytes Due to Fluid Drag on Pericellular Matrix, Journal of Biomechanics, Vol.34 (2001), pp.1375-1386.

(52) Jacobs, C.R., Yellowley, C.E., Davis, B.R., Zhou, Z., Cimbala, J.M. and Donahue, H.J., Differential Effect of Steady Versus Oscillating Flow on Bone Cells, Journal of 
Biomechanics, Vol.31 (1998), pp.969-976.

(53) Donahue, T.L., Haut, T.R., Yellowley, C.E., Donahue, H.J. and Jacobs, C.R., Mechanosensitivity of Bone Cells to Oscillating Fluid Flow Induced Shear Stress May Be Modulated by Chemotransport, Journal of Biomechanics, Vol.36 (2003), pp.1363-1371.

(54) Vatsa, A., Mizuno, D., Smit, T.H., Schmidt, C.F., MacKintosh, F.C. and Klein-Nulend, J., Bio Imaging of Intracellular NO Production in Single Bone Cells after Mechanical Stimulation, Journal of Bone and Mineral Research, Vol.21 (2006), pp.1722-1728.

(55) Nicolella, D.P., Moravits, D.E., Gale, A.M., Bonewald, L.F. and Lankford, J., Osteocyte Lacunae Tissue Strain in Cortical Bone, Journal of Biomechanics, Vol.39 (2006), pp.1735-1743.

(56) Rath Bonivtch, A., Bonewald, L.F. and Nicolella, D.P., Tissue Strain Amplification at the Osteocyte Lacuna: A Microstructural Finite Element Analysis, Journal of Biomechanics, Vol.40 (2007), pp.2199-2206.

(57) Burger, E.H. and Klein-Nulend, J., Mechanotransduction in Bone--Role of the Lacuno-Canalicular Network, The FASEB Journal, Vol.13, Suppl. (1999), pp.S101-S112.

(58) Turner, C.H. and Pavalko, F.M., Mechanotransduction and Functional Response of the Skeleton to Physical Stress: The Mechanisms and Mechanics of Bone Adaptation, Journal of Orthopaedic Science, Vol.3 (1998), pp.346-355.

(59) Pavalko, F.M., Chen, N.X., Turner, C.H., Burr, D.B., Atkinson, S., Hsieh, Y.F., Qiu, J. and Duncan, R.L., Fluid Shear-Induced Mechanical Signaling in MC3T3-E1 Osteoblasts Requires Cytoskeleton-Integrin Interactions, The American Journal of Physiology, Vol.275 (1998), pp.C1591-C1601.

(60) Ingber, D.E., Cellular Basis of Mechanotransduction, The Biological Bulletin, Vol.194 (1998), pp.323-327.

(61) Rubin, J., Rubin, C. and Jacobs, C.R., Molecular Pathways Mediating Mechanical Signaling in Bone, Gene, Vol.367 (2006), pp.1-16.

(62) Ingber, D. E., Integrins, Tensegrity, and Mechanotransduction, Gravitational and Space Biology Bulletin, Vol.10 (1997), pp.49-55.

(63) Hynes, R.O., Integrins: Versatility, Modulation, and Signaling in Cell Adhesion, Cell, Vol.69 (1992), pp.11-25.

(64) Schwartz, M.A., Schaller, M.D. and Ginsberg, M.H., Integrins: Emerging Paradigms of Signal Transduction, Annual Review of Cell and Developmental Biology, Vol.11 (1995), pp.549-599.

(65) Miyauchi, A., Gotoh, M., Kamioka, H., Notoya, K., Sekiya, H., Takagi, Y., Yoshimoto, Y., Ishikawa, H., Chihara, K., Takano-Yamamoto, T., Fujita, T. and Mikuni-Takagaki, Y., AlphaVbeta3 Integrin Ligands Enhance Volume-Sensitive Calcium Influx in Mechanically Stretched Osteocytes, Journal of Bone and Mineral Metabolism, Vol.24 (2006), pp.498-504.

(66) Kamioka, H., Sugawara, Y., Murshid, S.A., Ishihara, Y., Honjo, T. and Takano-Yamamoto, T., Fluid Shear Stress Induces Less Calcium Response in a Single Primary Osteocyte Than in a Single Osteoblast: Implication of Different Focal Adhesion Formation, Journal of Bone and Mineral Research, Vol.21 (2006), pp.1012-1021.

(67) Aarden, E.M., Nijweide, P.J., Van Der Plas, A., Alblas, M.J., Mackie, E.J., Horton, M.A. and Helfrich, M.H., Adhesive Properties of Isolated Chick Osteocytes in Vitro, Bone, Vol.18 (1996), pp.305-313.

(68) Tanaka-Kamioka, K., Kamioka, H., Ris, H. and Lim, S.S., Osteocyte Shape Is Dependent on Actin Filaments and Osteocyte Processes Are Unique Actin-Rich Projections, Journal of Bone and Mineral Research, Vol.10 (1998), pp.1555-1568.

(69) Davidson, R.M., Tatakis, D.W. and Auerbach, A.L., Multiple Forms of Mechanosensitive Ion Channels in Osteoblast-Like Cells, Pflugers Archiv, Vol.416 (1990), pp.646-651.

(70) Duncan, R.L., Kizer, N., Barry, E.L., Friedman, P.A. and Hruska, K.A., Antisense 
Oligodeoxynucleotide Inhibition of a Swelling-Activated Cation Channel in Osteoblast-Like Osteosarcoma Cells, Proceedings of the National Academy of Sciences of the United States of America, Vol.93 (1996), pp.1864-1869.

(71) Kizer, N., Guo, X.L. and Hruska, K., Reconstitution of Stretch-Activated Cation Channels by Expression of the Alpha-Subunit of the Epithelial Sodium Channel Cloned from Osteoblasts, Proceedings of the National Academy of Sciences of the United States of America, Vol.94 (1997), pp.1013-1018.

(72) Miyauchi, A., Notoya, K., Mikuni-Takagaki, Y., Takagi, Y., Goto, M., Miki, Y., Takano-Yamamoto, T., Jinnai, K., Takahashi, K., Kumegawa, M., Chihara, K. and Fujita, T., Parathyroid Hormone-Activated Volume-Sensitive Calcium Influx Pathways in Mechanically Loaded Osteocytes, The Journal of Biological Chemistry, Vol.275 (2000), pp.3335-3342.

(73) Li, J., Liu, D., Ke, H.Z., Duncan, R.L. and Turner, C.H., The P2X7 Nucleotide Receptor Mediates Skeletal Mechanotransduction, The Journal of Biological Chemistry, Vol.280 (2005), pp.42952-42959.

(74) Praetorius, H.A. and Spring, K.R., The Renal Cell Primary Cilium Functions As a Flow Sensor, Current Opinion in Nephrology and Hypertension, Vol.12 (2003), pp.517-520.

(75) Malone, A.M., Anderson, C.T., Tummala, P., Kwon, R.Y., Johnston, T.R., Stearns, T. and Jacobs, C.R., Primary Cilia Mediate Mechanosensing in Bone Cells by a Calcium-Independent Mechanism, Proceedings of the National Academy of Sciences of the United States of America, Vol.104 (2007), pp.13325-13330.

(76) Jiang, J.X. and Cherian, P.P., Hemichannels Formed by Connexin 43 Play an Important Role in the Release of Prostaglandin $\mathrm{E}_{2}$ by Osteocytes in Response to Mechanical Strain, Cell Communication and Adhesion, Vol.10 (2003), pp.259-264.

(77) Berridge, M.J., Bootman, M.D. and Lipp, P., Calcium--A Life and Death Signal, Nature, Vol.395 (1998), pp.645-648.

(78) Liedert, A., Kaspar, D., Blakytny, R., Claes, L. and Ignatius, A., Signal Transduction Pathways Involved in Mechanotransduction in Bone Cells, Biochemical and Biophysical Research Communications, Vol.349 (2006), pp.1-5.

(79) Chen, N.X., Ryder, K.D., Pavalko, F.M., Turner, C.H., Burr, D.B., Qiu, J. and Duncan, R.L., $\mathrm{Ca}^{2+}$ Regulates Fluid Shear-Induced Cytoskeletal Reorganization and Gene Expression in Osteoblasts, American Journal of Physiology, Cell Physiology, Vol.278 (2000), pp.C989-C997.

(80) Yan, C., Takahashi, M., Okuda, M., Lee, J.D. and Berk, B.C., Fluid Shear Stress Stimulates Big Mitogen-Activated Protein Kinase 1 (BMK1) Activity in Endothelial Cells. Dependence on Tyrosine Kinases and Intracellular Calcium, The Journal of Biological Chemistry, Vol.274 (1999), pp.143-150.

(81) Li, J., Duncan, R.L., Burr, D.B. and Turner, C.H., L-Type Calcium Channels Mediate Mechanically Induced Bone Formation in Vivo, Journal of Bone and Mineral Research, Vol.17 (2002), pp.1795-1800.

(82) Davis, K.L., Martin, E., Turko, I.V. and Murad, F., Novel Effects of Nitric Oxide, Annual Review of Pharmacology and Toxicology, Vol.41 (2001), pp.203-236.

(83) Fan, X., Roy, E., Zhu, L., Murphy, T.C., Ackert-Bicknell, C., Hart, C.M., Rosen, C., Nanes, M.S. and Rubin, J., Nitric Oxide Regulates Receptor Activator of Nuclear Factor-Kappab Ligand and Osteoprotegerin Expression in Bone Marrow Stromal Cells, Endocrinology, Vol.145 (2004), pp.751-759.

(84) Klein-Nulend, J., Van Der Plas, A., Semeins, C.M., Ajubi, N.E., Frangos, J.A., Nijweide, P.J. and Burger, E.H., Sensitivity of Osteocytes to Biomechanical Stress in Vitro, The FASEB Journal, Vol.9 (1995), pp.441-445.

(85) Klein-Nulend, J., Helfrich, M.H., Sterck, J.G., MacPherson, H., Joldersma, M., Ralston, S.H., Semeins, C.M. and Burger, E.H., Nitric Oxide Response to Shear Stress by Human 
Bone Cell Cultures Is Endothelial Nitric Oxide Synthase Dependent, Biochemical and Biophysical Research Communications, Vol.250 (1998), pp.108-114.

(86) Fan, X., Roy, E.M., Murphy, T.C., Nanes, M.S., Kim, S., Pike, J.W. and Rubin, J., Regulation of RANKL Promoter Activity Is Associated with Histone Remodeling in Murine Bone Stromal Cells, Journal of Cellular Biochemistry, Vol.93 (2004), pp.807-818.

(87) Mikuni-Takagaki, Y., Kakai, Y., Satoyoshi, M., Kawano, E., Suzuki, Y., Kawase, T. and Saito, S., Matrix Mineralization and the Differentiation of Osteocyte-Like Cells in Culture, Journal of Bone and Mineral Research, Vol.10 (1995), pp.231-242.

(88) Zhang, K., Barragan-Adjemian, C., Ye, L., Kotha, S., Dallas, M., Lu, Y., Zhao, S., Harris, M., Harris, S.E., Feng, J.Q. and Bonewald, L.F., E11/gp38 Selective Expression in Osteocytes: Regulation by Mechanical Strain and Role in Dendrite Elongation, Molecular and Cellular Biology, Vol.26 (2006), pp.4539-4552.

(89) Alford, A.I., Jacobs, C.R. and Donahue, H.J., Oscillating Fluid Flow Regulates Gap Junction Communication in Osteocytic MLO-Y4 Cells by an ERK1/2 MAP Kinase-Dependent Mechanism, Bone, Vol.33 (2003), pp.64-70.

(90) Genetos, D.C., Kephart, C.J., Zhang, Y., Yellowley, C.E. and Donahue, H.J., Oscillating Fluid Flow Activation of Gap Junction Hemichannels Induces ATP Release from MLO-Y4 Osteocytes, Journal of Cellular Physiology, Vol.212 (2007), pp.207-214.

(91) Liu, S., Gupta, A. and Quarles, L.D., Emerging Role of Fibroblast Growth Factor 23 in a Bone-Kidney Axis Regulating Systemic Phosphate Homeostasis and Extracellular Matrix Mineralization, Current Opinion in Nephrology and Hypertension, Vol.16 (2007), pp.329-335.

(92) Yang, W., Lu, Y., Kalajzic, I., Guo, D., Harris, M.A., Gluhak-Heinrich, J., Kotha, S., Bonewald, L.F., Feng, J.Q., Rowe, D.W., Turner, C.H., Robling, A.G. and Harris, S.E., Dentin Matrix Protein 1 Gene Cis-Regulation: Use in Osteocytes to Characterize Local Responses to Mechanical Loading in Vitro and in Vivo, The Journal of Biological Chemistry, Vol.280 (2005), pp.20680-20690.

(93) Skerry, T.M. and Suva, L.J., Investigation of the Regulation of Bone Mass by Mechanical Loading: From Quantitative Cytochemistry to Gene Array, Cell Biochemistry and Function, Vol.21 (2003), pp.223-229.

(94) Reijnders, C.M., Bravenboer, N., Holzmann, P.J., Bhoelan, F., Blankenstein, M.A. and Lips, P., In Vivo Mechanical Loading Modulates Insulin-Like Growth Factor Binding Protein-2 Gene Expression in Rat Osteocytes, Calcified Tissue International, Vol.80 (2007), pp.137-143.

(95) Inaoka, T., Lean, J.M., Bessho, T., Chow, J.W., Mackay, A., Kokubo, T. and Chambers, T.J., Sequential Analysis of Gene Expression after an Osteogenic Stimulus: c-fos Expression Is Induced in Osteocytes, Biochemical and Biophysical Research Communications, Vol.217 (1995), pp.264-270.

(96) Bonewald, L.F., Mechanosensation and Transduction in Osteocytes, Bonekey Osteovision, Vol.3 (2006), pp.7-15.

(97) Aguirre, J.I., Plotkin, L.I., Stewart, S.A., Weinstein, R.S., Parfitt, A.M., Manolagas, S.C. and Bellido, T., Osteocyte Apoptosis Is Induced by Weightlessness in Mice and Precedes Osteoclast Recruitment and Bone Loss, Journal of Bone and Mineral Research, Vol.21 (2006), pp.605-615.

(98) Gu, G., Mulari, M., Peng, Z., Hentunen, T.A. and Vaananen, H.K., Death of Osteocytes Turns off the Inhibition of Osteoclasts and Triggers Local Bone Resorption, Biochemical and Biophysical Research Communications, Vol.335 (2005), pp.1095-1101.

(99) Heino, T.J., Hentunen, T.A. and Vaananen, H.K., Osteocytes Inhibit Osteoclastic Bone Resorption through Transforming Growth Factor-Beta: Enhancement by Estrogen, Journal of Cellular Biochemistry, Vol.85 (2002), pp.185-197.

(100) Verborgt, O., Gibson, G.J. and Schaffler, M.B., Loss of Osteocyte Integrity in Association 
with Microdamage and Bone Remodeling after Fatigue in Vivo, Journal of Bone and Mineral Research, Vol.15 (2000), pp.60-67.

(101) Kurata, K., Heino, T.J., Higaki, H. and Vaananen, H.K., Bone Marrow Cell Differentiation Induced by Mechanically Damaged Osteocytes in 3D Gel-Embedded Culture, Journal of Bone and Mineral Research, Vol.21 (2006), pp.616-625.

(102) Kurata, K., Fukunaga, T., Matsuda, J. and Higaki, H., Role of Mechanically Damaged Osteocytes in the Initial Phase of Bone Remodeling, International Journal of Fatigue, Vol.29 (2007), pp.1010-1018.

(103) Jiang, J.X. and Gu, S., Gap Junction- and Hemichannel-Independent Actions of Connexins, Biochimica et Biophysica Acta, Vol.1711 (2005), pp.208-214.

(104) Taylor, A.F., Saunders, M.M., Shingle, D.L., Cimbala, J.M., Zhou, Z. and Donahue, H.J., Mechanically Stimulated Osteocytes Regulate Osteoblastic Activity via Gap Junctions, American Journal of Physiology, Cell Physiology, Vol.292 (2007), pp.C545-C552.

(105) Heino, T.J., Hentunen, T.A. and Vaananen, H.K., Conditioned Medium from Osteocytes Stimulates the Proliferation of Bone Marrow Mesenchymal Stem Cells and Their Differentiation into Osteoblasts, Experimental Cell Research, Vol.294 (2004), pp.458-468.

(106) Pitsillides, A.A., Rawlinson, S.C., Suswillo, R.F., Bourrin, S., Zaman, G. and Lanyon, L.E., Mechanical Strain-Induced NO Production by Bone Cells: A Possible Role in Adaptive Bone (Re)Modeling?, The FASEB Journal, Vol.9 (1995), pp.1614-1622.

(107) Smit, T.H., Burger, E.H. and Huyghe, J.M., A Case for Strain-Induced Fluid Flow As a Regulator of BMU-Coupling and Osteonal Alignment, Journal of Bone and Mineral Research, Vol.17 (2002), pp.2021-2029.

(108) Marotti, G., Ferretti, M., Muglia, M.A., Palumbo, C. and Palazzini, S.A., Quantitative Evaluation of Osteoblast-Osteocyte Relationships on Growing Endosteal Surface of Rabbit Tibiae, Bone, Vol.13 (1992), pp.363-368.

(109) Martin, R.B., Does Osteocyte Formation Cause the Nonlinear Refilling of Osteons?, Bone, Vol.26 (2000), pp.71-78.

(110) Van Bezooijen, R.L., Ten Dijke, P., Papapoulos, S.E. and Lowik, C.W., SOST/Sclerostin, an Osteocyte-Derived Negative Regulator of Bone Formation, Cytokine and Growth Factor Reviews, Vol.16 (2005), pp.319-327.

(111) Lu, Y., Xie, Y., Zhang, S., Dusevich, V., Bonewald, L.F. and Feng, J.Q., DMP1-Targeted Cre Expression in Odontoblasts and Osteocytes, Journal of Dental Research, Vol.86 (2007), pp.320-325.

(112) Feng, J.Q., Ward, L.M., Liu, S., Lu, Y., Xie, Y., Yuan, B., Yu, X., Rauch, F., Davis, S.I., Zhang, S., Rios, H., Drezner, M.K., Quarles, L.D., Bonewald, L.F. and White, K.E., Loss of DMP1 Causes Rickets and Osteomalacia and Identifies a Role for Osteocytes in Mineral Metabolism, Nature Genetics, Vol.38 (2006), pp.1310-1315.

(113) Tatsumi, S., Ishii, K., Amizuka, N., Li, M., Kobayashi, T., Kohno, K., Ito, M., Takeshita, S. and Ikeda, K., Targeted Ablation of Osteocytes Induces Osteoporosis with Defective Mechanotransduction, Cell Metabolism, Vol.5 (2007), pp.464-475. 